\title{
The Search for Molecular Corks Beyond Carbon Monoxide: A Quantum Mechanical Study of N-Heterocyclic Carbene Adsorption on $\mathrm{Pd} / \mathrm{Cu}(111)$ and $\mathrm{Pt} / \mathrm{Cu}(111)$ Single Atom Alloys
}

Scott Simpson

Department of Chemistry, St. Bonaventure University, St. Bonaventure, NY, 14778, United States

\begin{abstract}
:
Periodic Density Functional Theory calculations reveal the potential application of 10 imidazole based N-heterocyclic carbenes to behave as "molecular corks" for hydrogen storage on single atom alloys, comprised of $\mathrm{Pd} / \mathrm{Cu}(111)$ or $\mathrm{Pt} / \mathrm{Cu}(111)$. Calculations show that functionalizing the $\mathrm{NHC}$ with different electron withdrawing/donating functional groups results in different binding energies of the NHC with the alloy surfaces. The results are compared to DFT calculations of carbon monoxide bound to these alloys. The Huynh electronic parameter (is calculated for several simple imidazole NHCs to gauge $\sigma$-donor ability, while Se-NMR of and P-NMR calculations of selenourea derivatives and carbene-phosphinidene adducts, respectively, have been utilized to gauge $\pi$-acidity of the NHCs. It is demonstrated that consideration of both $\sigma$ and $\pi$ donating/accepting ability must be considered when predicting the surface-adsorbate binding energy. It was found that electron withdrawing groups tend to weaken the NHC-surface interaction while electron withdrawing substituents tend to strengthen the interaction.
\end{abstract}

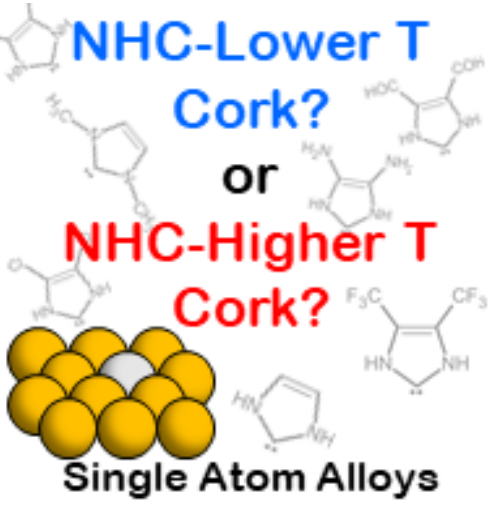

\section{Introduction:}

Hydrogen is one of the major alternatives to replace fossil fuels as it has been deemed a clean and renewable energy resource. Hydrogen additionally has the added benefit of having a high energy density with an energy content approximately three times higher than that of gasoline when considering a per weight basis.[1-3] However, before hydrogen usage in transportation, stationary, and portable application can become practically viable hydrogen storage is required to make this dream a reality. Currently a very large liquid or pressurized tank of $\mathrm{H}_{2}$ gas would be required to be stored on board a vehicle for transportation purposes. Not only is this unpractical for transportation but also is extremely dangerous for numerous reasons. If interstellar travel is ever to become commonplace like it is on different sci-fi television shows (Cowboy Bebop comes to my mind), then a safe, condensed, and high capacity storage device will need to be developed.

To these ends, we propose utilizing a relatively new phenomena, the "molecular corking effect", to solve this conundrum. However, before a device can be built, we must understand how to 
exert control over every facet of this newly determined effect which has great potential for the storage of hydrogen.[4,5] The screening of potential systems via computations will allow for inexpensive and rapid investigations into targeted systems which show the greatest promise for hydrogen storage. However, due to the relatively recent discovery of this phenomena, there have not been many experimental or theoretical investigations.

The molecular corking effect utilizes single-atom alloys (SAAs). SAAs are metal surfaces that utilize a small amount of catalytically active metals on a relatively inert metal and are known for their exceptional performance, drastic cost reduction, and selectivity.[6,7,48] Figure 1 shows a visual example of a $\mathrm{Pt} / \mathrm{Cu}(111) \mathrm{SAA}$ and a schematic representation of the molecular corking effect. The molecular corking effect has been show by Lucci et al., where small amounts of Pt on a $\mathrm{Cu}(111)$ surface is favorable for $\mathrm{H}_{2}$ activation, spill-over, and release of hydrogen from the surface.[8] They determined that the individual $\mathrm{Pt}$ atoms easily dissociate $\mathrm{H}_{2}$ which then spills over onto the $\mathrm{Cu}$ surface as atomistic hydrogen $(\mathrm{H})$. On the $\mathrm{Cu}$ surface, atomistic hydrogen is very mobile however only recombines to form $\mathrm{H}_{2}$ at the $\mathrm{Pt}$ sites and desorbs from the surface at these points, as $\mathrm{Cu}(111)$ is not capable of dissociating hydrogen gas in ultra high vacuum conditions.[9] This spill-over has also been shown to work for Pd-Au surface alloys.[10]

The process of the molecular cork effect follows these simple steps: 1) molecular hydrogen $\left(\mathrm{H}_{2}\right)$ adsorbs to a $\mathrm{Pd} / \mathrm{Cu}$ or $\mathrm{Pt} / \mathrm{Cu}$ alloy; 2) the $\mathrm{H}_{2}$ bond ruptures due to the interaction of the molecule with the catalytically active metal (Pd or Pt have recently been used) forming atomistic hydrogen $(\mathrm{H})$ on the noble metal $(\mathrm{Cu})$ surface; 3$)$ selective adsorption of ligands to the catalytically active metal prevents the recombination of atomistic hydrogen; 4) temperature is used to dissociate the ligand from the surface, allowing for the recombination of atomistic hydrogen and the liberation of $\mathrm{H}_{2}$ from the surface. In this mechanism, the surface behaves as the bottle while the ligand behaves as the cork. Recently, carbon monoxide $(\mathrm{CO})$ was utilized as a cork for a $\mathrm{Pd} / \mathrm{Cu}$ or a $\mathrm{Pt} / \mathrm{Cu}$ alloy.[4,5] The previously mentioned study provides evidence that this molecular corking effect does function, the cork (CO) raised the desorption temperature of $\mathrm{H}_{2}$ from about $210 \mathrm{~K}$ to approximately $250 \mathrm{~K}$ on $\mathrm{Pd} / \mathrm{Cu}$ and from $230 \mathrm{~K}$ to $280 \mathrm{~K}$ on $\mathrm{Pt} / \mathrm{Cu}$, respectfully. A schematic representation can be seen in Figure 1. 
a)

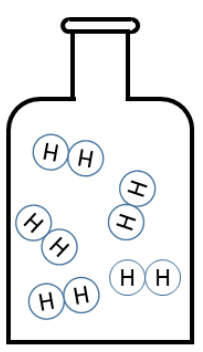

b)

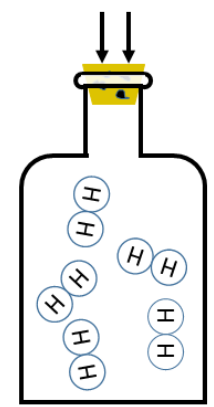

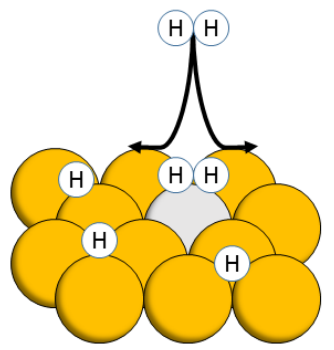
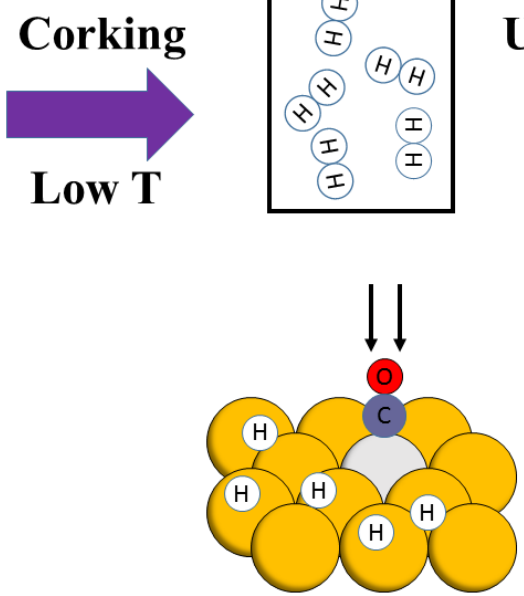

c)
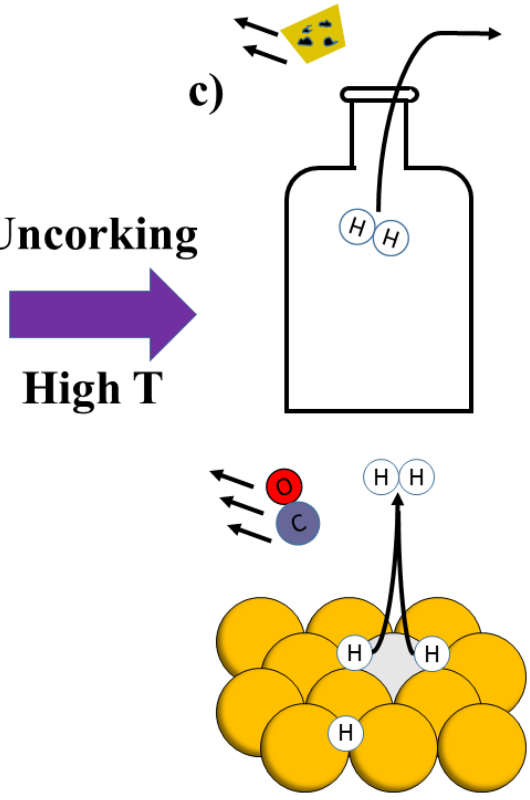

Figure 1: A schematic representation of the molecular corking effect where the bottle represents the metal surface and the cork represents the ligand carbon monoxide (CO). The top of the figure represents the simplified concept while the bottom represents a more chemical representation. Part (a) show the decomposition of the $\mathrm{H}_{2}$ molecule and storage phase, part (b) show the corking phase using $\mathrm{CO}$ as the cork, and part (c) shows the uncorking phase where the molecular cork leaves allowing the hydrogen to escape from the surface. White/orange/light gray/red/dark gray spheres represent hydrogen/copper/platinum/oxygen/carbon, respectively.

It is clear that the temperature at which the hydrogen will leave the metal surface will need to extend above $250 \mathrm{~K}$ for practical use. However, it is not just carbon monoxide that can be utilized as a molecular cork. Experiments show that ethyl benzene can also be utilized as a molecular cork on $\mathrm{Pd} / \mathrm{Cu}$ alloys.[4]

Another class of compounds, N-heterocyclic carbenes (NHCs) have been widely used and developed in organometallic chemistry as their $\sigma / \pi$ acceptor/donor abilities have been found to be quiet tunable to arrive at a desired molecular geometries.[11-13] ${ }^{77} \mathrm{Se} \mathrm{NMR}$ and ${ }^{31} \mathrm{P}$ NMR have been used to gauge the $\pi$ acceptor abilities of NHCs, while ${ }^{13} \mathrm{C}$ NMR has been used to gauge their $\sigma$ donating ability and show a path to modulate the electronic structure of these class of compounds.[13-16] In fact, DFT has been used to investigate NHCs on $\mathrm{Au}, \mathrm{Cu}, \mathrm{Ag}$, and Pt surfaces, showing that NHCs can behave as molecular anchors on these metals.[17] However, there is still minimal studies on NHCs utilize SAAs have be undertaken. A recent studies have shown that derivatization of a NHC can be used to change the binding mode of NHCs on copper and gold surfaces using scanning tunneling microscopy (STM), X-ray photoelectron spectroscopy (XPS), other surface techniques, and DFT.[17-20] In an attempt to replace thiols, NHCs have been shown to be a promising replacement as molecular anchors as use of sensors, microelectronics, surface protectants, and even drug delivery applications on gold surfaces.[2127] The aforementioned experimental results clearly show that NHCs are excellent molecular anchors for transition-metal surfaces, and therefore would be potentially viable molecular corks. 
To demonstrate this, we provide preliminary evidence to show that the substituents on the NHCs can be used to modulate the strength of the interaction between surface and adsorbate.

\section{Computational Details}

All periodic DFT calculations were conducted using the VASP.5.3.3 software package and the vdW-optB88 functional to account for dispersion forces.[28-29] The projector augmented wave (PAW) method was used to treat the core states along with a planewave energy cut-off of 500 $\mathrm{eV}$, and the $\mathrm{C} / \mathrm{N} / \mathrm{O} / \mathrm{F} 2 \mathrm{~s} / 2 \mathrm{p}, \mathrm{H} 1 \mathrm{~s}, \mathrm{~S} / \mathrm{P} 3 \mathrm{~s} / 3 \mathrm{p}, \mathrm{Cu} 4 \mathrm{~s} / 3 \mathrm{~d}, \mathrm{Pd} 5 \mathrm{~s} / 4 \mathrm{~d}$, and $\mathrm{Pt} 6 \mathrm{~s} / 5 \mathrm{~d}$ electrons were treated explicitly. The $\Gamma$-Centered Monkhorst-Pack scheme was used to generate k-point meshes, and we employed a 9x9x1 K-mesh, which gave rise to energies that were converged to within $1 \mathrm{meV} /$ atom of energies compute with a larger k-mesh. A three-layer 48 atom slab was used to simulate the $\mathrm{Cu}(111)$ surface. During geometry optimizations involving the slab, the adsorbate and top layer of the slab were permitted to relax while the bottom two layers of the slab were fixed. In the case of periodic SAA calculations, a single atom of $\mathrm{Cu}$ in the surface layer of the slab was replaced by Pd or Pt atom, similar to what is described to Darby at el.[5] A dipole correction was applied along the direction perpendicular to the metal surface using the LDIPOL tag as implemented in VASP. Isolated molecules were optimized in a $15 \AA$ x $15 \AA$ x 15 $\AA$ unit cell. To determine the impact of the inclusion of approximate non-local dispersion, the revised PBE functional (revPBE) was used.[30] The results of these calculations are contained in the supporting information (SI).

Molecular calculations were conducted using the TURBOmole software package [31] using the BP86 functional [32,33] and a def2-TZVPD basis [34,35] for each element. Vibrational frequencies were calculated for these optimized geometries to ensure a minimum on the potential energy surface was determined. NMR shielding constant calculations were with the previously described basis functions and functional for all systems other than our Huynh Electronic Parameter (HEP) calculations. In calculations of the HEP, the dhf-TZVP basis for each of the lighter elements and the dhf-ecp was utilized for Pd atoms.

\section{Results and Discussion}

Our initial investigation reported herein utilize the simple NHC of with an imidazole backbone, as seen in Figure 2. We have selected a variety of different substituents that will impact the $\sigma / \pi$ donor/acceptor properties of the NHCs. We have previously shown that functionalization can impact the surface-adsorbate interface for benzene derivatives on $\mathrm{Cu}(111)$.[36] First, we consider a variety of different NMR techniques that have been shown to quantify the $\sigma / \pi$ donor/acceptor interactions of different NHCs using molecular DFT calculations. Then we quantify the overall interaction of the NHCs with $\mathrm{Pd} / \mathrm{Cu}(111)$ or $\mathrm{Pt} / \mathrm{Cu}(111)$ SAAs using periodic optB88-vdW calculations. Finally, we then compare the energetics of these NHCs to determine plausible higher-temperature molecular corks. 


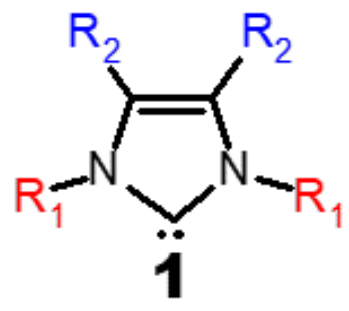

Figure 2: The N-heterocyclic carbene imidazole backbone considered in this study. $R_{1}$ and $\mathbf{R}_{2}$ have been modified with the different substituents listed in Table 1.

\section{Gauging $\pi$-acidity of the NHCs}

It is well known that NHCs not only interact with transition metals via $\sigma$-interactions, but also $\pi$ interactions. As previously stated, Se-NMR and P-NMR has been utilized to gauge $\pi$-acidity. To these ends, we have conducted NMR calculations of the selenoureas and carbenephosphinidene adducts of these NHCs.[13] The results of these calculations can be seen in Table 1 .

\begin{tabular}{|c|c|c|c|c|c|c|c|}
\hline $\mathbf{R}_{\mathbf{1}}$ & $\mathbf{R}_{\mathbf{2}}$ & $\mathbf{S e}-\boldsymbol{\sigma}(\mathbf{p p m})$ & $\boldsymbol{\sigma} \mathbf{d}(\mathbf{p p m})$ & $\boldsymbol{\sigma}_{\mathbf{p}}(\mathbf{p p m})$ & $\mathbf{P}-\boldsymbol{\sigma}(\mathbf{p p m})$ & $\boldsymbol{\sigma}_{\mathbf{d}}(\mathbf{p p m})$ & $\boldsymbol{\sigma}_{\mathbf{p}}(\mathbf{p p m})$ \\
\hline $\mathrm{H}$ & $\mathrm{H}$ & 1696.8 & 3001.4 & -1304.6 & 289.7 & 949.0 & -659.3 \\
\hline $\mathrm{H}$ & $\mathrm{F}$ & 1651.0 & 3000.8 & -1349.9 & 282.4 & 947.7 & -665.3 \\
\hline $\mathrm{H}$ & $\mathrm{Cl}$ & 1615.6 & 3001.0 & -1385.4 & 277.4 & 948.2 & -670.8 \\
\hline $\mathrm{H}$ & $\mathrm{CH}$ & 1722.6 & 3002.1 & -1279.5 & 289.6 & 947.8 & -658.2 \\
\hline $\mathrm{CH}_{3}$ & $\mathrm{H}$ & 1710.1 & 3002.1 & -1292.0 & 307.4 & 947.8 & -640.4 \\
\hline $\mathrm{H}$ & $\mathrm{CF}_{3}$ & 1629.4 & 3002.3 & -1372.9 & 281.4 & 947.5 & -666.1 \\
\hline $\mathrm{H}$ & $\mathrm{NH}_{2}$ & 1722.3 & 3002.0 & -1279.2 & 291.0 & 947.2 & -656.1 \\
\hline $\mathrm{H}$ & $\mathrm{NO}_{2}$ & 1438.1 & 3001.3 & -1563.3 & 248.2 & 947.1 & -698.9 \\
\hline $\mathrm{H}$ & $\mathrm{COH}_{\mathrm{H}}$ & 1609.4 & 3001.5 & -1392.1 & 289.9 & 943.5 & -653.6 \\
\hline $\mathrm{H}$ & $\mathrm{N}\left(\mathrm{CH}_{3}\right)_{2}$ & 1767.7 & 3002.9 & -1235.2 & 288.0 & 946.0 & -658.0 \\
\hline
\end{tabular}

Table 1: Isotropic chemical shielding $(\sigma)$, diamagnetic shielding component $\left(\sigma_{d}\right)$ and paramagnetic shielding component $\left(\sigma_{p}\right)$ of selenourea and carbene-phosphinidene adducts for the NHC imidazole-based molecules calculated using TURBOMOLE, the BP86 density functional, and the def2-TZVPD basis set.

Our calculations show that the electron withdrawing groups, such as $-\mathrm{CF}_{3}$ or $-\mathrm{NO}_{2}$, lower the overall isotropic chemical shielding. It is apparent that the paramagnetic shielding component $\left(\sigma_{\mathrm{p}}\right)$ decreases as the more electron withdrawing the substituent is while the diamagnetic shielding component $\left(\boldsymbol{\sigma}_{\mathbf{d}}\right)$ remains essentially constant. The opposite can be said to be true for electron donating groups, such as $-\mathrm{CH}_{3}$, or $-\mathrm{N}\left(\mathrm{CH}_{3}\right)_{2}$ which the overall isotropic chemical shielding and $\sigma_{\mathrm{p}}$ values increase. Studies have shown that the more upfield/shielded the Se signal of the selenourea, the less $\pi$-acidic the NHC is.[13-16] The opposite is said to be true; the more downfield these signals, the more $\pi$-acidic the NHC. The most $\pi$-acidic groups were determined to be $-\mathrm{NO}_{2}$, and $-\mathrm{COH}$ while the least acidic were found to be $-\mathrm{NH}_{2},-\mathrm{CH}_{3}$, and $\mathrm{N}\left(\mathrm{CH}_{3}\right)_{2}$.

Generally, the Se- $\sigma$ trends match the P- $\sigma$, with some notable exceptions such as $-\mathrm{COH}$. We attribute this discrepancy to the number of energetically accessible conformers of the carbene- 
phosphinidene adducts, which can have widely different isotropic P- $\sigma$ values. While this is not an issue in experiment our calculations only account for one conformer in our calculations. This could be curbed by taking an average of a weighted Boltzmann distribution of the different conformers. However, we elect to draw trends from the selenoureas as their trends have been shown to experimentally match that of carbene-phosphinidene adducts[16] and as the Se does not have as much conformational flexibility as the phosphinidenes. However, these NMR signals provide only a gauge of the $\pi$-interactions of the NHCs. To gauge the $\sigma$-acidity/basicity, one must consider other parameters, such as the Huynh electronic parameter.

\section{Gauging $\sigma$-donor strength of the NHCs}

The Huynh electronic parameter (HEP) utilizes ${ }^{13} \mathrm{C}$ NMR spectroscopy to gauge the primarily $\sigma-$ donor strength of a ligand.[13,37,38] The carbene carbon signal of the ${ }^{i} \operatorname{Pr}_{2}$ bimy "reporter" ligand is used as the reporting metric of the HEP. When this signal is shifted more upfield (more shielded), the competing ligand is a weaker donor, while a downfield (less shielded) indicates a stronger donor ligand. HEP has been considered to be more capable of determining subtle variations in the ligand's electronic structure compared to other electronic parameters, such as the Tolman electronic parameter. We have calculated the HEP for the NHCs previously mentioned in this study (Table 2). The NHCs functionalized with $\mathrm{NO}_{2}$ and $\mathrm{CF}_{3}$ are the weakest $\sigma$-donor ligands while $\mathrm{N}\left(\mathrm{CH}_{3}\right)_{2}, \mathrm{NH}_{2}$, and $\mathrm{CH}_{3}$ functionalized $\mathrm{NHCs}$ were found to be the strongest $\sigma$-donor ligands.

\begin{tabular}{|c|c|c|}
\hline $\mathbf{R}_{\mathbf{1}}$ & $\mathbf{R}_{\mathbf{2}}$ & HEP (ppm) \\
\hline $\mathrm{H}$ & $\mathrm{H}$ & 196.5 \\
\hline $\mathrm{H}$ & $\mathrm{F}$ & 194.7 \\
\hline $\mathrm{H}$ & $\mathrm{Cl}$ & 194.8 \\
\hline $\mathrm{H}$ & $\mathrm{CH}_{3}$ & 197.4 \\
\hline $\mathrm{CH}_{3}$ & $\mathrm{H}$ & 198.4 \\
\hline $\mathrm{H}$ & $\mathrm{CF}_{3}$ & 193.8 \\
\hline $\mathrm{H}$ & $\mathrm{NH}_{2}$ & 197.6 \\
\hline $\mathrm{H}$ & $\mathrm{NO}_{2}$ & 191.7 \\
\hline $\mathrm{H}$ & $\mathrm{COH}_{2}$ & 193.3 \\
\hline $\mathrm{H}$ & $\mathrm{N}\left(\mathrm{CH}_{3}\right)_{2}$ & 196.9 \\
\hline
\end{tabular}

Table 2: The HEP isotropic $C$ chemical shift ( $\delta$ ) as calculated using TURBOMOLE, the BP86 density functional, and the dhf-TZVP basis set. TMS was used as a reference standard with the same computational methodology.

\section{Periodic Calculations}

Using periodic calculations, we have conducted geometry optimizations for the interaction of these NHC interacting with a SAA $\mathrm{Pd} / \mathrm{Cu}(111)$ and $\mathrm{Pt} / \mathrm{Cu}(111)$ alloys at a surface coverage of 0.01442 molecules $/ \AA^{2}$. First, one must probe the potential energy surface of this surfaceadsorbate system to gauge the potential of these adsorbate molecules prowess as molecular corks. Does the NHC even prefer to bind to the catalytical active metal? Without this binding site preference, the adsorbate molecule would not be useable as a molecular cork. To confirm this, we conduct a series of calculations where the NHC is optimized at different positions on the metal surface. In one calculation, the NHC interacts with one of the copper atoms in the surface layer whereas the NHC interacts with the $\mathrm{Pd} / \mathrm{Pt}$ atom in the other calculation. The results of these calculations are tabulated in Table 3. We have determined all of the tested NHCs favor 
binding to the catalytically active metals, rather than a copper surface atom by approximately $5.0 / 11 \mathrm{kcal} / \mathrm{mol}$ for $\mathrm{Pd} / \mathrm{Cu}(111)$ and $\mathrm{Pt} / \mathrm{Cu}(111)$, respectively. The lowest energy geometries of the NHC-alloy interactions were found to adopt a geometry with the plane of the NHC molecule perpendicular to the plane of the surface rather than parallel to the surface plane, similar to Figure 3.

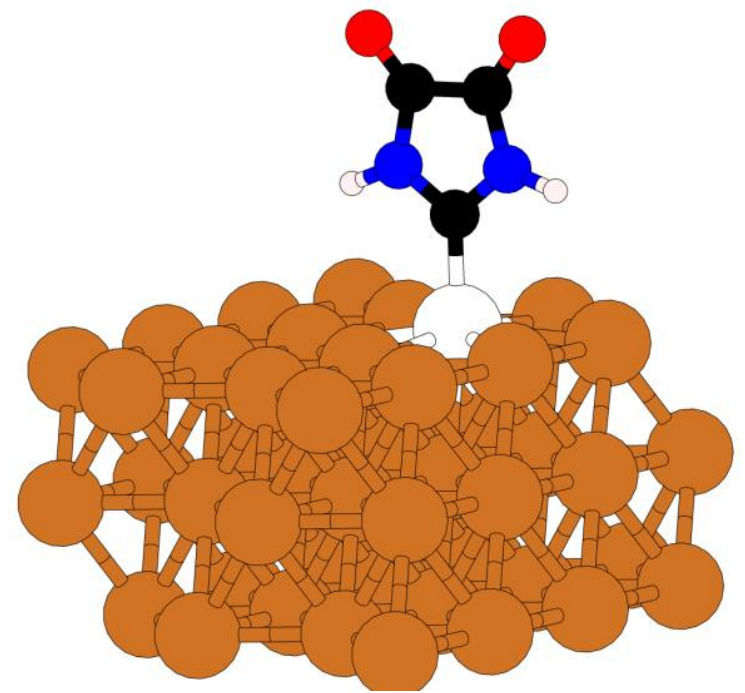

Figure 3: The optimized simulation cell of an $\mathrm{NHC}\left(\mathrm{R}_{1}=\mathrm{H}, \mathrm{R}_{2}=\mathrm{O}\right)$ on $\mathrm{Pd} / \mathrm{Cu}(111)$. Hydrogen, carbon, nitrogen, oxygen, copper, and palladium atoms are colored white, black, blue, red, orange, and silver, respectively.

Next, the strength of the surface-adsorbate interaction, the binding energy, must be considered to rule out unsuitable corks. The binding energy (BE) was calculated using the following formula:

$$
\mathrm{BE}=\mathrm{E}_{\text {surf-ads }}-\mathrm{E}_{\text {surf }}-\mathrm{E}_{\text {ads }}
$$

, where $\mathrm{E}_{\text {surf-ads }}$ is the energy of the SAA surface interacting with the NHC adsorbate, $\mathrm{E}_{\text {surf }}$ is the energy of the isolated SAA surface, and $\mathrm{E}_{\text {abs }}$ is the energy of the isolated NHC molecule. Therefore, a negative energy show an energetically favorable interaction. Generally, the NHCs have a higher binding energy on the Pt-Cu SAA compared to the Pd-Cu SAA. The average bond length of the NHC-metal bond is longer on $\mathrm{Pd} / \mathrm{Cu}(111)$ in comparison to $\mathrm{Pt} / \mathrm{Cu}(111)$.

Considering the influence of the substituents, the more electron withdrawing groups, such as $\mathrm{R}_{2}=\mathrm{NO}_{2}, \mathrm{COH}, \mathrm{CF}_{3}$, have a weaker $\mathrm{BE}$ compared to the unfunctionalized $\mathrm{NHC}$ while electron donating groups, such as $\mathrm{R}_{2}=\mathrm{N}\left(\mathrm{CH}_{3}\right)_{2}, \mathrm{CH}_{3}, \mathrm{NH}_{2}$, have a stronger binding energy for both alloys. Some general trends can be established based upon our previously mentioned isotropic $\mathrm{Se}$ shielding and HEP values:

1. The more $\pi$-acidic the NHC, and therefore the lower Se isotropic shielding, the weaker the binding energy compared to the unfunctionalized imidazole.

2. The lower the HEP value, the weaker the surface-adsorbate interaction. 


\begin{tabular}{|c|c|c|c|c|c|c|c|c|c|}
\hline \multirow[b]{2}{*}{$\mathbf{R}_{1}$} & \multirow[b]{2}{*}{$\mathbf{R}_{2}$} & \multicolumn{4}{|c|}{$\mathrm{Pd} / \mathrm{Cu}(111) \mathrm{SAA}$} & \multicolumn{4}{|c|}{$\mathrm{Pt} / \mathrm{Cu}(111) \mathrm{SAA}$} \\
\hline & & $\begin{array}{c}\text { C-Pd } \\
\text { Dist }(\AA)\end{array}$ & $\begin{array}{c}\text { Ediff }_{\text {(kcal/mol) }} \\
\text { (kcalong }\end{array}$ & $\begin{array}{c}\text { BE } \\
\text { (kcal/mol) }\end{array}$ & $\begin{array}{c}\text { qNHC } \\
(\mathbf{e})\end{array}$ & $\begin{array}{c}\text { C-Pt } \\
\text { Dist } \\
(\AA)\end{array}$ & $\begin{array}{c}\text { Ediff }_{\text {(kcal/mol) }} \\
\text { (kcalon }\end{array}$ & $\begin{array}{c}\text { BE } \\
\text { (kcal/mol) }\end{array}$ & $\begin{array}{l}\text { qNHC } \\
(\mathbf{e})\end{array}$ \\
\hline $\mathrm{H}$ & $\mathrm{H}$ & 2.0612 & 5.0 & -43.0 & +0.011 & 2.0176 & 11.6 & -49.5 & -0.011 \\
\hline $\mathrm{H}$ & $\mathrm{F}$ & 2.0500 & 4.1 & -40.2 & -0.041 & 2.0121 & 10.0 & -46.4 & -0.057 \\
\hline $\mathrm{H}$ & $\mathrm{Cl}$ & 2.0452 & 4.1 & -41.6 & -0.102 & 2.0061 & 10.0 & -47.9 & -0.105 \\
\hline $\mathrm{H}$ & $\mathrm{CH}_{3}$ & 2.0592 & 4.3 & -46.3 & -0.008 & 2.0194 & 10.1 & -52.9 & +0.028 \\
\hline $\mathrm{CH}_{3}$ & $\mathrm{H}$ & 2.1175 & 6.0 & -39.8 & -0.205 & 2.0518 & 11.4 & -45.4 & -0.217 \\
\hline $\mathrm{H}$ & $\mathrm{CF}_{3}$ & 2.0530 & 5.9 & -40.7 & -0.127 & 2.0082 & 11.7 & -47.1 & -0.113 \\
\hline $\mathrm{H}$ & $\mathrm{COH}$ & 2.0473 & 5.0 & -31.3 & -0.119 & 2.0027 & 11.8 & -37.9 & -0.102 \\
\hline $\mathrm{H}$ & $\mathrm{NH}_{2}$ & 2.0493 & 3.5 & -46.5 & +0.010 & 2.0161 & 9.5 & -53.0 & -0.031 \\
\hline $\mathrm{H}$ & $\mathrm{NO}_{2}$ & 2.0579 & 10.9 & -40.7 & -0.222 & 2.0109 & 11.5 & -47.1 & -0.264 \\
\hline $\mathrm{H}$ & $\mathrm{N}\left(\mathrm{CH}_{3}\right)_{2}$ & 2.0472 & 4.3 & -49.3 & +0.007 & 2.0124 & 11.4 & -56.1 & -0.049 \\
\hline
\end{tabular}

Table 3: The carbene carbon-Pd/Pt bond length (C-Pd Dist), the differences in energy between the $\mathrm{NHC}$ binding via $\mathrm{Pd} / \mathrm{Pt}$ vs. a copper surface atom ( $\mathrm{E}_{\text {diff), }}$, the binding energy (BE), and overall Bader charges of the adsorbed NHC (qNHC) for differently substituted NHCs using optB88-vdW. Energies are reported in $\mathrm{kcal} / \mathrm{mol}$. The carbene carbon to $\mathbf{P d} / \mathbf{P t}$ atom is also reported in angstroms. Charges are reported in e (elementary charge).

To determine the flow of charge between the surface and the adsorbate, Bader charges were computed for each system.[39] Generally, NHCs bound to the $\mathrm{Pt} / \mathrm{Cu}(111)$ experienced a large magnitude of charge transfer than those on $\mathrm{Pd} / \mathrm{Cu}(111)$ for a given functionalization. In the majority of the cases, the NHC acquired a surplus amount of charge while the surface lost charge. The exceptions were for the NHCs substituted with $\mathrm{R}_{1}=\mathrm{H} / \mathrm{R}_{2}=\mathrm{H}, \mathrm{NH}_{2}, \mathrm{~N}\left(\mathrm{CH}_{3}\right)_{2}$ on $\mathrm{Pd} / \mathrm{Cu}(111)$ and only $\mathrm{R}_{1}=\mathrm{H} / \mathrm{R}_{2}=\mathrm{CH}_{3}$ for $\mathrm{Pt} / \mathrm{Cu}(111)$.

However, another factor that will dictate the NHC-surface interaction beyond modulation of the electronic structure is steric hindrance. This is clearly illustrated when comparing the interaction of the $\mathrm{NHC}$ that has been substituted with $\mathrm{CH}_{3} / \mathrm{H}$ and $\mathrm{H} / \mathrm{CH}_{3}, \mathrm{R}_{1} / \mathrm{R}_{2}$ respectively. The binding energy of $\mathrm{CH}_{3} / \mathrm{H}$ is greater than that of the $\mathrm{H} / \mathrm{CH}_{3}$ substituted $\mathrm{NHC}$ by approximately $7 \mathrm{kcal} / \mathrm{mol}$, yet the calculated shielding of the two NHCs, contained in Table 1, indicate that these molecules have similar $\pi$-acidity. Additionally, the C-Pd lengths and the C-Pt lengths are significantly longer for the $\mathrm{CH}_{3} / \mathrm{H} \mathrm{NHC}$ compared to the $\mathrm{H} / \mathrm{CH}_{3}$. Excluding the sterically hindered case of $\mathrm{H} / \mathrm{CH}_{3}$, it is clear to see that the strength of the NHC-surface interaction can be modulated via the substituents on the NHC as the binding energies range of approximately $20 \mathrm{kcal} / \mathrm{mol}$ of the tested adsorbates.

It is also important to know that coverage of adsorbate molecules on the surface can influence the surface-adsorbate interaction.[40] To these ends we have optimized the simplest of our previously mentioned $\mathrm{NHCs}\left(\mathrm{R}_{1}=\mathrm{R}_{2}=\mathrm{H}\right)$ with varying surface coverages to demonstrate the impact of coverage on the binding energy (Table 4). We also make note that the surface coverage of $\mathrm{Pt} / \mathrm{Pd}$ atoms matches the coverage of molecules, as only one of these atoms is included in the simulation cell. Unsurprisingly, as the surface coverage increases the binding energy of the NHC to the alloy surface decreases for both $\mathrm{Pd} / \mathrm{Cu}(111)$ and $\mathrm{Pt} / \mathrm{Cu}(111)$. This is 
attributed to charge redistribution upon molecular adsorption and the intermolecular attraction between adjacent adsorbate molecules.[40-44] As seen for both alloys, increasing the molecular coverage decreases the magnitude of the binding energy by approximately $4 \mathrm{kcal} / \mathrm{mol}$ for the coverages considered herein. This demonstrates that surface coverage needs to be considered when considering a ligand's potential to behave as a molecular cork.

\begin{tabular}{|c|c|c|c|c|}
\cline { 2 - 5 } \multicolumn{1}{c|}{} & \multicolumn{2}{c|}{ Pd/Cu(111) SAA } & \multicolumn{2}{c|}{ Pt/Cu(111) SAA } \\
\hline $\begin{array}{c}\text { Coverage } \\
\left(\mathbf{m o l e c u l e s} / \mathbf{\AA}^{\mathbf{2}}\right)\end{array}$ & BE $(\mathbf{k c a l} / \mathbf{m o l})$ & $\mathbf{C - P d}$ Dist $(\mathbf{\AA})$ & BE $(\mathbf{k c a l} / \mathbf{m o l})$ & C-Pt Dist $(\AA)$ \\
\hline $8.653 \cdot 10^{-3}$ & -44.1 & 2.0549 & -50.9 & 2.0163 \\
\hline $1.082 \cdot 10^{-2}$ & -44.1 & 2.0561 & -50.7 & 2.0178 \\
\hline $1.442 \cdot 10^{-2}$ & -43.0 & 2.0612 & -49.5 & 2.0176 \\
\hline $2.163 \cdot 10^{-2}$ & -42.8 & 2.0468 & -49.3 & 2.0129 \\
\hline
\end{tabular}

Table 4: The binding energy (BE) for differently surface coverages of $\mathrm{NHCs}$ on $\mathrm{Pd} / \mathrm{Cu}(111)$ and $\mathrm{Pt} / \mathrm{Cu}(111)$ using optB88-vdW, reported in $\mathrm{kcal} / \mathrm{mol}$.

\section{Categorizing the Plausible Molecular Corks}

We have also calculated the binding energy of carbon monoxide (CO) on both alloys. Similar to the study by Darby et. al,[5] we found that the most favorable binding site of $\mathrm{CO}$ on $\mathrm{Pt} / \mathrm{Cu}(111)$ was on the Pt top site. We conclude that the same binding site trend for $\mathrm{Pd} / \mathrm{Cu}(111)$, with the $\mathrm{CO}$ bound to a top site above the $\mathrm{Pd}$, is the most energetically preferable by approximately 15 $\mathrm{kcal} / \mathrm{mol}$. They also determined that the binding energy of $\mathrm{CO}$ to $\mathrm{Pt} / \mathrm{Cu}(111)$ was $-27.4 \mathrm{kcal} / \mathrm{mol}$ using periodic RPBE calculations. Using optB88-vdW, we calculate the binding energy of CO to these alloys to be $-30.8 \mathrm{kcal} / \mathrm{mol}$ for $\mathrm{Pt} / \mathrm{Cu}(111)$ and $-24.2 \mathrm{kcal} / \mathrm{mol}$ for $\mathrm{Pd} / \mathrm{Cu}(111)$ at a coverage of 0.01442 molecules $/ \AA^{2}$, respectively. A Bader charge analysis shows that the CO adsorbate molecule accumulates $0.103 \mathrm{e}$ on $\mathrm{Pd} / \mathrm{Cu}(111)$ and $0.270 \mathrm{e}$ on $\mathrm{Pt} / \mathrm{Cu}(111)$.

Our traditional GGA revPBE calculations, which did not include non-local correlation, at coverage of 0.01075 molecules $/ \AA^{2}$, show a weaker binding energy for each SAA. The binding energy was calculated to be $-19.4 \mathrm{kcal} / \mathrm{mol}$ for $\mathrm{Pd} / \mathrm{Cu}(111)$ and $-27.2 \mathrm{kcal} / \mathrm{mol}$ for $\mathrm{Pt} / \mathrm{Cu}(111)$. A Bader charge analysis shows that the $\mathrm{CO}$ adsorbate molecule accumulates $0.188 \mathrm{e}$ on $\mathrm{Pd} / \mathrm{Cu}(111)$ and $0.211 \mathrm{e}$ on $\mathrm{Pt} / \mathrm{Cu}(111)$. This shows the impact of dispersion forces in surfaceadsorbate systems is required.

The Polanyi-Wigner equation indicates that systems with a higher binding energy will have a higher desorption temperature, assuming other parameters such as coverage and frequency factor, remain constant.[45] Therefore, based upon binding energies of the NHCs to the alloy surfaces, we have split the NHCs listed in Table 3 into higher/lower temperature molecular corks. In all cases the NHCs should desorb at a temperature higher than CO on both alloys. A summary of the results can be seen in Figure 4. The lowest temperature cork is predicted to be the $\mathrm{NHC}\left(\mathrm{R}_{1}=\mathrm{COH}, \mathrm{R}_{2}=\mathrm{H}\right)$ while $\mathrm{NHC}\left(\mathrm{R}_{1}=\mathrm{H}, \mathrm{R}_{2}=\mathrm{N}\left(\mathrm{CH}_{3}\right)_{2}\right)$ is predicted to be the highest temperature cork for both $\mathrm{Pd} / \mathrm{Cu}(111)$ and $\mathrm{Pt} / \mathrm{Cu}(111)$. However, a useful cork will have a desorption temperature that is fitting for its application. Therefore, we plan to pursue a way to predict the desorption temperature of these NHCs using computationally expensive molecular dynamics simulations in the future. 


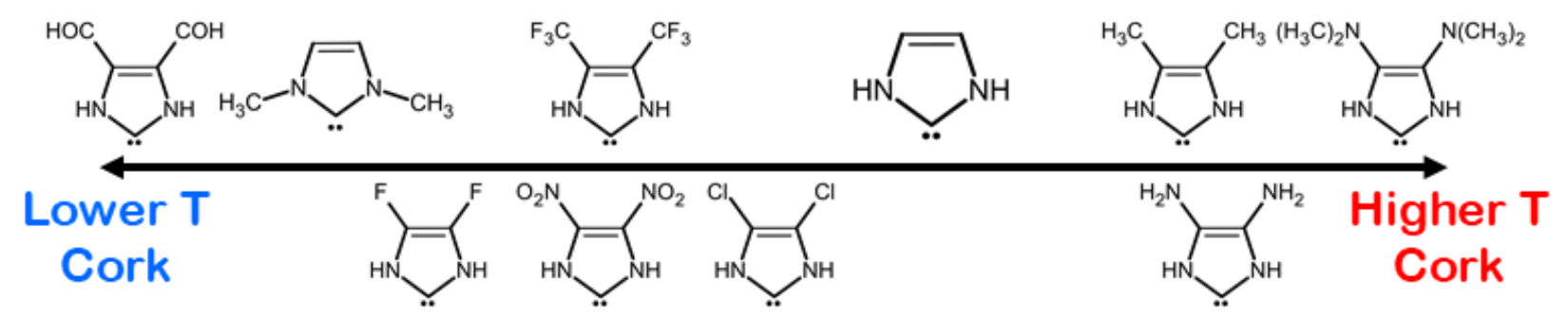

Figure 4: Approximate scale of molecular cork ability of N-heterocyclic carbene adsorbates on $\mathrm{Pd} / \mathrm{Cu}(111)$ and on $\mathrm{Pt} / \mathrm{Cu}(111)$.

\section{Conclusions}

In summary, we have predicted the capacity of several imidazole-based NHCs to behave as molecular corks for hydrogen storage applications on $\mathrm{Pd} / \mathrm{Cu}(111)$ and $\mathrm{Pt} / \mathrm{Cu}(111)$ alloys using periodic DFT-vdW calculations. Calculations show that functionalizing the NHC with different electron withdrawing/donating functional groups results in different binding energies of the NHC with the alloy surfaces. The surface coverage was also shown to impact the binding energy of simple NHC to the alloys. HEP and Se-NMR calculations were calculated and used to rationalize binding trends. Therefore, both $\sigma$ and $\pi$ donating/accepting ability must be considered when predicting the surface-adsorbate binding energy. Finally, functionalization for the imidazole-based NHC can modulated the desired application/desorption temperature.

\section{Acknowledgements}

The author acknowledge National Science Foundation (Award \#1904825) for support of this research, and the Donors of the American Chemical Society Petroleum Research Fund (PRF58954-UNI5). The author also acknowledge Professor Kellie Gast for providing useful comments. Any opinions, findings, conclusions, or recommendations expressed in this publication are those of the author and do not necessarily reflect the view of the NSF.

\section{References}

[1] Suh, M.P; Park, H.J.; Prasadm T.K.; Lim, D.W. Hydrogen Storage in Metal-Organic Frameworks. Chem. Rev., 2012, 122, 782-835.

[2] Grochala, W.; Edwards, E.P. Thermal Decomposition of Non-Interstitial Hydrides for the Storage and Production of Hydrogen. Chem. Rev., 2004, 104, 1283-1315.

[3] Hirscher, M.; Yartys, V.A.; Baricco, M.; von Colbe, J.B.; Blanchard, D.; Bowman, R.C.; Broom, D.P.; Buckley, C.E.; Chang, F.; Chen, P.; et al. Materials for hydrogen-based energy storage - past, recent progress and future outlook. J. Alloy Compd., 2020, 827, 153548.

[4] Marcinkowski, M. D.; Jewell, A. D.; Stamatakis, M.; Boucher, M. B.; Lewis, E. A.; Murphy, C. J.; Kyriakou G.; Sykes, E. C. H. Controlling a spillover pathway with the molecular cork effect. Nature Mat., 2013, 12, 523-528. 
[5] Darby, M.T.; Lucci, F.R.; Marcinkowski, M.D.; Therrien, A.J.; Michaelides, A.; Stamatakis, M.; Sykes, E.C.H. Carbon Monoxide Mediated Hydrogen Release from PtCu Single-Atom Alloys: The Punctured Molecular Cork Effect. J. Phys. Chem. C, 2019, 123, 10419-10428.

[6] G. Kyriakou, G.;Boucher, M.B.; Jewell, A.D.; Lewis, E.A.; Lawton, T.J.; Baber, A.E.; Tierney, H.L.; Flytzani-Stephanopoulos, M.; Sykes, E.C.H. Isolated Metal Atom Geometries as a Strategy for Selective Heterogeneous Hydrogenations. Science, 2012, 335, 1209-121

[7] Niancai Cheng, N.; Lei Zhang, L.; Kieran Doyle-Davis, K.; Sun, X. Single-Atom Catalysts: From Design to Application. Electrochem. En. Rev., 2019, 2, 539-573.

[8] F. Lucci, F.; Marcinkowski, M.; Lawton,T.; Sykes, E.C.H. $\mathrm{H}_{2}$ activation and spillover on catalytically relevant Pt-Cu single atom alloys. J. Phys. Chem. C, 2015, 119, 24351-24357.

[9] Anger, G.; Winkler, A.; Rendulic, K. Adsorption and desorption kinetics in the systems $\mathrm{H}_{2} / \mathrm{Cu}(111)$, $\mathrm{H}_{2} / \mathrm{Cu}(110)$ and $\mathrm{H}_{2} / \mathrm{Cu}(100)$. Surf. Sci., 1989, 220, 1-17.

[10] Lucci, F. R.; Darby, M. T.; Mattera, M. F. G.; Ivimey, C. J.; Therrien, A. J.; Michaelides, A.; Stamatakis, M.; Sykes, E. C. H. Controlling Hydrogen Activation, Spillover, and Desorption with $\mathrm{Pd}-\mathrm{Au}$ Single-Atom Alloys. J. Phys. Chem. Lett., 2016, 7, 480-485.

[11] Grineva, A.A.; Filippov, O.A.; Nefedov, S.E.; Lugan, N.; César, V.; Valyaev, D.A. Direct Access to IMesF and IMesF2 by Electrophilic Fluorination of Abnormal N-Heterocyclic Carbenes.

Organometallics, 2019, 38, 2330-2337.

[12] Bernhammer, J.C.; Frison, G.; Huynh, H.V. Electronic Structure Trends in N-Heterocyclic Carbenes (NHCs) with Varying Number of Nitrogen Atoms and NHC-Transition-Metal Bond Properties. Chem.

Eur. J., 2013, 19, 12892-12905.

[13] Huynh, H.V. Electronic Properties of N-Heterocyclic Carbenes and Their Experimental

Determination. Chem. Rev., 2018, 118, 9457-9492

[14] Back, O.; Henry-Ellinger, M.; Martin, C.D.; Martin, D.; Bertrand, G. ${ }^{31}$ P NMR Chemical Shifts of Carbene-Phosphinidene Adducts as an Indicator of the $\pi$-Accepting Properties of Carbenes. Angew.

Chem. Int. Ed., 2013, 52, 2939-2943.

[15] Falivene, L,; Cavallo, L. Theoretical NMR spectroscopy of N-heterocyclic carbenes and their metal complexes. Coord Chem. Rev., 2017, 344, 101-114.

[16] Vummaleti, S.V.C; Nelson, D.J.; Poater, A.; Gómez-Suárez, A.; Cordes, D.B.; Slawin, A.M.Z.;

Nolan, S.P.; Cavallo, L. What can NMR spectroscopy of selenoureas and phosphinidenes teach us about the p-accepting abilities of N-heterocyclic carbenes? Chem. Sci., 2015, 6, 1895-1904

[17] Chang, K.; Chen, J.G.; Lu, Q.; Cheng, M.J. Grand Canonical Quantum Mechanical Study of the Effect of the Electrode Potential on N-Heterocyclic Carbene Adsorption on Au Surfaces. J. Phys. Chem. C., 2017, 121, 24618-24625.

[18] Larrea, C.R.; Baddeley, C.J.; Narouz, M.R.; Mosey, N.J.; Horton, J.H.; Crudden, C.M. NHeterocyclic Carbene Self-assembled Monolayers on Copper and Gold: Dramatic Effect of Wingtip Groups on Binding, Orientation and Assembly. ChemPhysChem, 2017, 18, 3536.

[19] Bakker, A.; Timmer, A.; Kolodzeiski, E.; Freitag, M.; Gao, H.Y.; Mönig, H.; Amirjalayer,

S.; Glorius, F.; Fuchs, H. Elucidating the Binding Modes of N-Heterocyclic Carbenes on a Gold Surface. J. Am. Chem. Soc., 2018, 140, 11889-11892.

[20] Chang, K.;Chen, J.G.;Lu, Q.; Cheng, M.J. Quantum Mechanical Study of N-Heterocyclic Carbene Adsorption on Au Surfaces. J. Phys. Chem. A., 2017, 121, 2674-2682.

[21] Zhukhovitskiy, A. V.; MacLeod, M. J.; Johnson, J. A. Carbene Ligands in Surface Chemistry: From Stabilization of Discrete Elemental Allotropes to Modification of Nanoscale and Bulk Substrates. Chem.

Rev., 2015, 115, 11503-11532.

[22] Weidner, T.; Baio, J. E.; Mundstock, A.; Grosse, C.; Karthauser, S.; Bruhn, C.; Siemeling, U. NHCBased Self-Assembled Monolayers on Solid Gold Substrates. Aust. J. Chem., 2011, 64, 1177-1179.

[23] Zhukhovitskiy, A. V.; Mavros, M. G.; Van Voorhis, T.; Johnson, J. A. Addressable Carbene Anchors for Gold Surfaces. J. Am. Chem. Soc., 2013, 135, 7418-7421. 
[24] Crudden, C. M.; Horton, J. H.; Ebralidze, II; Zenkina, O. V.; McLean, A. B.; Drevniok, B.; She, Z.; Kraatz, H. B.; Mosey, N. J.; Seki, T.; et al. Ultra Stable Self-Assembled Monolayers of N-Heterocyclic Carbenes on Gold. Nat. Chem., 2014, 6, 409-414.

[25] Crudden, C. M.; Horton, J. H.; Narouz, M. R.; Li, Z.; Smith, C. A.; Munro, K.; Baddeley, C. J.; Larrea, C. R.; Drevniok, B.; Thanabalasingam, B.; et al. Simple Direct Formation of Self-Assembled NHeterocyclic Carbene Monolayers on Gold and Their Application in Biosensing. Nat. Commun., 2016, 7 , 12654.

[26] Wang, G.; Ruhling, A.; Amirjalayer, S.; Knor, M.; Ernst, J. B.; Richter, C.; Gao, H. J.; Timmer, A.; Gao, H. Y.; Doltsinis, N. L.; et al. Ballbot-Type Motion of N-Heterocyclic Carbenes on Gold Surfaces. Nat. Chem., 2016, 9, 152-156.

[27] Engel, S.; Fritz, E. C.; Ravoo, B. J. New Trends in the Functionalization of Metallic Gold: From Organosulfur Ligands to N-Heterocyclic Carbenes. Chem. Soc. Rev., 2017, 46, 2057-2075

[28] Klimeš, J.; Bowler, D. R.; Michaelides, A. Van der Waals density functionals applied to solids. Phys. Rev. B, 2011, 83, 195131.

[29] Klimeš, J.; Bowler, D. R.; Michaelides, A. Chemical accuracy for the van der Waals density functional. J. Phys.-Condens. Mat., 2009, 22, 022201.

[30] Perdew, J. P.; Burke, K.; Ernzerhof, M. Generalized gradient approximation made simple. Phys. Rev. Lett., 1996, 77, 3865-3868.

[31] TURBOmole v7.3.

[32] Perdew, J. P., Density-functional approximation for the correlation energy of the inhomogeneous electron gas. Phys. Rev. B 1986, 33, 8822-8824.

[33] Becke, A. D., Density-functional exchange-energy approximation with correct asymptotic behaviour. Phys. Rev. A 1988, 38, 3098-3100.

[34] Rappoport, D.; Furche, F., Property-optimized gaussian basis sets for molecular response calculations. J. Chem. Phys. 2010, 133, 134105.

[35] Welgend, F.; Ahlrichs, R. Balanced basis sets of split valence, triple zeta valence and quadruple zeta valence quality for $\mathrm{H}$ to Rn: design and assessment of accuracy. Phys. Chem. Chem. Phys., 2005, 7, 32973305.

[36] Simpson, S.; Zurek, E. Substituted Benzene Derivatives on the $\mathrm{Cu}(111)$ Surface. J. Phys. Chem. C, 2012, 116, 12636-12643.

[37] Teng, Q.; Huynh, H.V. A unified ligand electronic parameter based on ${ }^{13} \mathrm{C}$ NMR spectroscopy of Nheterocyclic carbene complexes. Dalton Trans., 2017, 46, 614-627.

[38] Huynh, H.V.; Han, Y.; Jothibasu, R.; Tang, J.A. ${ }^{13}$ C NMR Spectroscopic Determination of Ligand Donor Strengths Using N-Heterocyclic Carbene Complexes of Palladium 9II0, Organometallics, 2009, 28, 5395-5404.

[39] Tang, W.; Sanville, E.; Henkelman, G. A Grid-Based Bader Analysis Algorithm without Lattice Bias. J. Phys.: Condens. Matter, 2009, 21, 084204.

[40] Simpson, S.; Kunkel, D.A.; Hooper, J.; Nitz, J.; Dowben, P.A.; Routaboul, L.; Braunstein, P.; Doudin, B.; Enders, A.; Zurek, E. Coverage-dependent interactions at the organics-metal interface: Quinonoid zwitterions on au(111). J. Phys. Chem. C, 2013, 117, 16406-16415.

[41] Bagus, P. S.; Staemmler, V.; Wöll, C. Exchangelike Effects for Closed-Shell Adsorbates: Interface Dipole and Work Function. Phys. Rev. Lett., 2002, 89, (096104), 1-4.

[42] Jewell, A. D.; Simpson, S. M.; Enders, A.; Zurek, E.; Sykes, E. C. H. Magic Electret Clusters of 4Fluorostyrene on Metal Surfaces. J. Phys. Chem. Lett., 2012, 3, 2069-2075.

[43] Rojas, G.; Simpson, S.; Chen, X.; Kunkel, D. A.; Nitz, J.; Xiao, J.; Dowben, P. A.; Zurek, E.; Enders, A. Surface State Engineering of Molecule-Molecule Interactions. Phys. Chem. Chem. Phys., 2012, 14, 4971-4976.

[44] Colin J. Murphy, C. J.; Miller, D. P.; Simpson, S.; Baggett, A.; Pronschinske, A.; Liriano, M. L.; Therrien, A. J.; Enders, A.; Liu, S.-Y.; Zurek, E.; et al Charge Transfer Induced Magic Cluster Formation of Azaborine Heterocycles on Noble Metal Surfaces. J. Phys. Chem. C., 2016, 120, 6020-6030. 
[45] Murphy, C. J.; Baggett, A.; Miller, D. P.; Simpson, S.; Marcinkowski, M. D.; Mattera, M. F. G.; Pronschinske, A.; Therrien, A.; Liriano, M. L.; Zurek, E.; et al. Effect of BN/CC isosterism on thermodynamics of surface and bulk binding; 1,2-dihydro-1,2-azaborine vs. benzene. J. Phys. Chem. C., 2015, 17, 12265-12272.

[46] Dewar, M. J. S. A review of $\pi$-complex theory. Bull. Soc. Chim. Fr., 1951, 18, C79. [47] Chatt, J.; Duncanson, L. A. Olefin co-ordination compounds. Part III. Infra-red spectra and structure: attempted preparation of acetylene complexes. J. Chem. Soc., 1953, 2939-2947.

[48] Hannagan, R.T.; Giannakakis, G.; Flytzani-Stephanopoulos, M.; Sykes, C.H. Single-Atom Alloy Catalysis. Chem. Rev., 2020, 230, 12044-12088. 